\title{
Nottingham Staphylococcus aureus population study: prevalence of MRSA among elderly people in the community
}

\author{
Hajo Grundmann, Adriana Tami, Satoshi Hori, Muhammad Halwani, Richard Slack
}

The spread of methicillin resistant Staphylococcus aureus (MRSA) has caused problems in most hospitals in the United Kingdom in the past decade. ${ }^{1}$ The extent to which the community serves as a reservoir for MRSA is unknown despite the growing recognition of MRSA as a community pathogen in various countries. ${ }^{2}$ We investigated the prevalence of nasal carriage of MRSA in a sample of people aged 65 and over who live in their own homes and represent the elderly population in the Greater Nottingham Health District, where MRSA is endemic in hospitals. ${ }^{3}$

\section{Participants, methods, and results}

We used electoral ward level statistics from 1991 to combine the catchment areas of seven large general practices and provide a study population of which the demographic composition (age, sex, social class, ethnicity, and proportion of elderly people living alone) was representative of the Nottingham Health District, which in most respects is similar to England as a whole. ${ }^{4}$ With the general practitioners' cooperation, we invited 1615 randomly selected people aged 65 or over to take part in the study, excluding those whose permanent address was a residential or nursing home. We carried out the study at the time of administration of influenza vaccinations on the premises of the participating surgeries. Of those invited, 1047 (64.8\%) elderly people presented for the investigation, and we enrolled 962 into the study. Samples consisted of swabs taken from both anterior nares. We used standard laboratory protocols to enrich and identify methicillin susceptible $S$ aureus and MRSA and used SmaI macrorestriction to type them genetically. We collected data on baseline demographic variables as well as specific risk factors. We used the $\chi^{2}$ test for univariate analysis of categorical variables, multivariate logistic regression to identify independent risk factors, and ward based Jarman deprivation scores to stratify data by socioeconomic characteristics. ${ }^{5}$

The sample comprised $1 \%$ of the population of the Nottingham Health District aged 65 and over. We found nasal carriage of methicillin susceptible $S$ aureus in 257 people $(26.7 \%$, 95\% confidence interval $24.1 \%$ to $29.8 \%$ ). We isolated MRSA from eight people. The population prevalence of MRSA was 8 (3 to 14) per 1000 population. We identified no risk factors for carriage of methicillin susceptible $S$ aureus. Carriage of MRSA was associated with several risk factors in univariate analysis (table), and two of these remained independently associated after logistic regressionhospital admission in the six months before the investigation (adjusted odds ratio 13.0, 2.5 to 68.2) and diabetes $(6.8,1.33$ to 34.3$)$. The presence of chronic skin ulcers was strongly associated, as a confounder, with both carriage of MRSA and previous hospital admission. Carriage of MRSA was independent of deprivation scores, indicating no association with lower living standards. All MRSA isolates were indistinguishable from the epidemic MRSA type 15 by genetic typing. This clone has become widely prevalent in English hospitals and was also the most common MRSA strain in the two major hospitals in Nottingham at the time of investigation. $^{3}$

\section{Comment}

In contrast to its continuous occurrence as the major nosocomial pathogen in England, MRSA has not encroached into the community to a large extent,

Division of

Microbiology and Infectious Diseases, Queen's Medical

Centre, University

Hospital

Nottingham,

Nottingham

NG7 2UH

Hajo Grundmann

consultant for clinical microbiology and infectious diseases

Satoshi Hori visiting scientist

Muhammad

Halwani

PhD student

continued over

BMJ 2002;324:1365-6

Univariate and multivariate analysis of risk factors for carriage of methicillin resistant Staphylococcus aureus (MRSA) in the community $(n=962)$

\begin{tabular}{|c|c|c|c|c|}
\hline Potential risk factors & $\begin{array}{c}\text { No (\%) } \\
\text { carrying MRSA }\end{array}$ & $\begin{array}{l}\text { Total No } \\
\text { of patients }\end{array}$ & $\begin{array}{l}\text { Odds ratio } \\
(95 \% \mathrm{CI})\end{array}$ & $P$ value \\
\hline \multicolumn{5}{|l|}{ Univariate analysis* } \\
\hline \multicolumn{5}{|c|}{ Not significantly associated with outcome } \\
\hline \multicolumn{5}{|l|}{ Age (years): } \\
\hline $65-74$ & $2(0.35)$ & 572 & 1 & \\
\hline$\geqslant 75$ & $6(1.54)$ & 389 & $4.5(0.89-22.2)$ & 0.07 \\
\hline \multicolumn{5}{|l|}{ Sex: } \\
\hline Female & $4(0.78)$ & 515 & 1 & \\
\hline Male & $4(0.89)$ & 447 & $0.87(0.21-3.5)$ & 0.8 \\
\hline \multicolumn{5}{|c|}{ Previous stay in nursing home: } \\
\hline No & $8(0.84)$ & 948 & 1 & \\
\hline Yes & $0(0)$ & 14 & $0.0(0.0-43.4)$ & 0.7 \\
\hline
\end{tabular}

\begin{tabular}{lllll}
\hline No of visits to general practitioner in the past year: & & & \\
\hline $0-3$ & $5(0.70)$ & 717 & 1 & 0.4 \\
\hline$>3$ & $3(1.22)$ & 245 & $1.78(0.42-7.5)$ & 0.4
\end{tabular}

Use of antibiotic in past six months $(\mathrm{n}=957)$ :

\begin{tabular}{lcccc}
\hline Use of antibiotic in past six months $(\mathrm{n}=957)$ : & & & & \\
\hline No & $4(0.54)$ & 742 & $3.5(0.87-14.1)$ & 0.08 \\
\hline Yes & $4(1.86)$ & 215 & & \\
\hline Smoking habits $(\mathrm{n}=572):$ & & & & \\
\hline Never smoked & $2(0.90)$ & 223 & $1.73(0.31-9.6)$ & 0.5 \\
\hline Ex-smoker & $4(1.54)$ & 259 & $1.24(0.10-13.8)$ & 0.9 \\
\hline Current smoker & $1(1.11)$ & 90 & & \\
\hline
\end{tabular}

Significantly associated with outcome

Presence of wound that does not heal:

\begin{tabular}{lrrrr} 
Presence of wound that does not heal: & & & \\
\hline No & $6(0.65)$ & 928 & 1 & \\
\hline Yes & $2(5.9)$ & 34 & $9.6(1.86-49.4)$ & 0.001 \\
\hline
\end{tabular}

Hospital admission in past six months:

\begin{tabular}{lllll}
\hline No & $2(0.25)$ & 811 & 1 & \\
\hline Yes & $6(3.97)$ & 151 & $16.7(3.3-83.7)$ & $<0.001$ \\
\hline
\end{tabular}

Diabetes $(n=960)$ :

\begin{tabular}{|c|c|c|c|c|}
\hline No & $5(0.57)$ & 879 & 1 & \\
\hline Yes & $3(3.70)$ & 81 & $6.7(1.58-28.7)$ & 0.003 \\
\hline \multicolumn{5}{|l|}{ Multivariate analysis $(n=959) \dagger$} \\
\hline Age group & & & $4.1(0.74-22.2)$ & 0.1 \\
\hline Jarman score & & & $1.05(0.98-1.12)$ & 0.1 \\
\hline Presence of wound that does not heal & & & $4.2(0.67-26.9)$ & 0.1 \\
\hline Hospital admission in past six months & & & $13.0(2.5-68.2)$ & 0.002 \\
\hline Diabetes & & & $6.7(1.33-34.3)$ & 0.02 \\
\hline
\end{tabular}

*Reporting crude odds ratios.

†Reporting adjusted odds ratios. 
Department of Infectious and Tropical Diseases, London School of Hygiene and Tropical Medicine, London

WC1E 7HT

Adriana Tami clinical lecturer

University of Nottingham and

Nottingham Health Authority

Richard Slack consultant for diseases control

Correspondence to: H Grundmann hajo.grundmann@ nottingham.ac.uk and the likelihood of finding healthy elderly people colonised with MRSA is relatively small. Carriage of MRSA can, however, be expected in patients who have chronic conditions or who have had recent admissions to hospital. MRSA in the community seems to be a consequence of a "spill over" of an uncontrolled hospital epidemic, and the few isolates found in the community are classic hospital strains. It continues to be safe to treat community acquired $S$ aureus infections in England with conventional antistaphylococcal agents effective against methicillin sensitive strains, and third line antibiotics should be considered only when typical risk factors can be ascertained.

Contributors: HG designed and coordinated the study. AT took part in every aspect of the study and carried out the statistical analysis. SH and MH carried out the bacteriological investigations and the genetic typing. All authors were involved in collecting samples and recording data. RS coordinated the general practitioner and community participation. HG wrote the manuscript and was supported by AT and RS in the final draft. $\mathrm{HG}$ and $\mathrm{RS}$ are the guarantors.

Funding: The study was supported by a grant from Nottingham Health Authority.

Competing interests: None declared.

1 Public Health Laboratory Service. Epidemic methicillin-resistant Staphy lococcus aureus. Commun Dis Rep CDR Wkly 1997;7:191.

2 Chambers HF. The changing epidemiology of Staphylococcus aureus? Emerg Infect Dis 2001;7:178-82.

3 Hori S, Sunley R, Tami A, Grundmann H. The Nottingham Staphylococcus aureus population study: prevalence of MRSA among the elderly in a university hospital. J Hosp Infect 2002;50:25-9.

4 Nottingham Health Authority. Aiming for health in the year 2000 Annual report of the Director of Public Health. Nottingham: Nottingham Health Authority, 1995:3-11.

5 Jarman B. Identification of underprivileged areas. BMJ 1983;286:1705-9. (Accepted 3 December 2001)

\title{
Longitudinal study of genital infection by herpes simplex virus type 1 in western Scotland over 15 years
}

\author{
Anne Scoular, John Norrie, Graeme Gillespie, Noreen Mir, W F Carman
}

Department of Genitourinary

Medicine,

Sandyford Initiative,

Glasgow G3 7NB

Anne Scoular

consultant physician

Robertson Centre

for Biostatistics,

University of

Glasgow, Glasgow

G12 8QQ

John Norrie

assistant director

West of Scotland

Specialist Virology

Centre, Gartnavel

General Hospital,

Glasgow G12 0XN

W F Carman

director

Graeme Gillespie

biomedical scientist

Department of

Genitourinary

Medicine, Russell

Institute, Paisley

PA1 1UR

Noreen Mir

consultant physician

Correspondence to:

A Scoular

anne@scoular.

demon.co.uk

BMJ 2002;324:1366-7
Although herpes simplex virus type 2 (HSV-2) is regarded as causing most cases of genital herpes, preliminary reports suggest that the type 1 virus (HSV-1) is increasingly the cause of infection. ${ }^{1}$ Recurrence rates, viral shedding, and the mode of acquiring HSV-1 infection are different from those for HSV-2, so counselling and clinical management strategies may need to be revised. We studied longitudinal trends in laboratory reports of genital HSV-1 infection.

\section{Methods and results}

The West of Scotland Specialist Virology Centre processes $99 \%$ of all herpes simplex virus culture samples in the region. All genital samples of herpes simplex processed between 1 January 1986 and 31 December 2000 were reviewed for source of referral, patient's sex and age (stratified into seven bands: $\leqslant 20,21-25,26-30$, $31-35,36-40,41-45$, and $>45$ years), and the type of virus isolated.

Samples were cultured and then typed using fluorescein labelled monoclonal antibodies to HSV-1 and HSV-2 (Syva Microtrak). From January 1999, the virus was detected and typed using a polymerase chain reaction method and restriction fragment length polymorphism. ${ }^{2}$ The referral patterns and age and sex profiles of patients did not change during the period of analysis.

We compared the proportion of HSV-1 in all positive swabs between sexes and ages using $\chi^{2}$ tests, and over the three year time bands by the Cochran Armitage trend test (both overall and within four subgroups with age categorised as $\leqslant 25$ years or $>25$ years for each sex) using SAS 8.2.

Of 10547 swabs, the virus was identified in 3181 (30\%); 3126 were typed, $1530(49 \%)$ as HSV-1 and
$1596(51 \%)$ as HSV-2. Of the swabs testing positive for HSV, 2004 (63\%) were from women and 1177 (37\%) were from men. Age was recorded for 3099 (97.4\%) patients, with $555(18 \%)$ aged $\leqslant 20,885(29 \%)$ aged 21-25, $686(22 \%)$ aged 26-30, $413(13 \%)$ aged 31-35, $239(8 \%)$ aged 36-40, $159(5 \%)$ aged 41-45, and 162 $(5 \%)$ aged $>45$ years. The origin of the request to detect the virus was recorded for 10476 (99\%) samples: $7579(72 \%)$ were from genitourinary medicine clinics, $678(6 \%)$ from general practice, $223(2 \%)$ from family planning clinics, and 1996 (19\%) from other sources.

HSV-1 was strongly associated with female sex and younger age $(\mathrm{P}<0.0001)$. Over the entire study period,

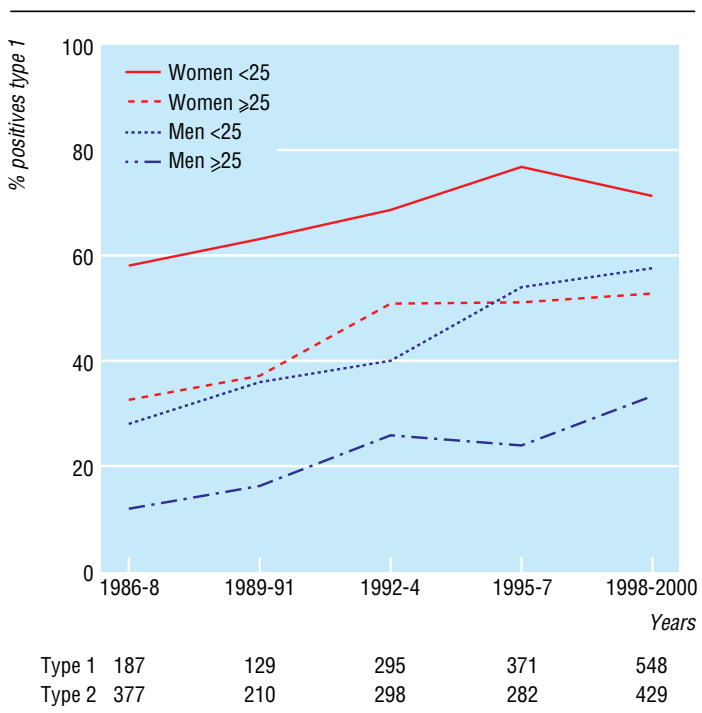

Proportion (\%) of herpes simplex virus test that were type 1 